\title{
CORRELAÇÃO ENTRE COMPREENSÃO LEITORA E PRODUÇÃO TEXTUAL EM MEIOS DIGITAIS
}

\author{
Vládia Maria Cabral Borges ${ }^{1 \times}$ \\ ${ }^{1}$ Universidade Federal do Ceará, Fortaleza, CE, Brasil
}

Keyla Maria Frota Lemos ${ }^{2+\infty}$

${ }^{2}$ Universidade do Estado do Rio Grande do Norte, Mossoró, RN, Brasil

Sâmela Rocha Barros Pereira ${ }^{1^{* * *}}$

${ }^{1}$ Universidade Federal do Ceará, Fortaleza, CE, Brasil

\begin{abstract}
Resumo
Esta pesquisa investigou a correlação entre níveis de compreensão leitora e fluência e esforço cognitivo na produção textual em computador, tablet e celular, fundamentada nos modelos cognitivos de produção escrita de Hayes e Flower (1980) e de Hayes (1996) e no modelo de Construção e Integração de Kintsch (1998). Foram utilizados os dados brutos de dois estudos anteriores e independentes. O Estudo 1 avaliou o esforço cognitivo e a fluência na produção, medidos através do tempo gasto na escrita dos textos e do número de palavras produzidas por minuto. O Estudo 2 avaliou os níveis de compreensão em testes realizados após a leitura de textos. Os procedimentos estatísticos aplicados foram o Coeficiente de Pearson e o Pairwise. As análises feitas evidenciaram uma forte correlação positiva
\end{abstract}

\footnotetext{
* Graduada em Letras pela Universidade Federal do Ceará (1979), mestre em Língua Inglesa pela Universidade Estadual do Ceará (1996) e doutora em Educação pela Universidade de Rhode Island, EUA (2006). É professora aposentada do Departamento de Estudos da Língua Inglesa, suas Literaturas e Tradução da Universidade Federal do Ceará. Atualmente, é professora colaboradora no Programa de Pós-Graduação em Linguística (PPGL-UFC), pesquisando e orientando nas áreas de: processamento textual; aquisição de segunda língua; metodologia de ensino-aprendizagem de línguas estrangeiras; e ensino-aprendizagem de línguas mediado por computador. E-mail: vladiaborges@gmail.com ORCID: https://orcid.org/0000-0002-2003-5695.

** Professora Adjunta do Departamento de Letras Estrangeiras da Universidade do Estado do Rio Grande do Norte (UERN) e coordenadora da Residência Pedagógica de Letras - Língua Inglesa. Atuou como coordenadora do curso de Especialização em Ensino e Aprendizagem de Línguas Estrangeiras e foi coordenadora do Programa Institucional de Bolsas de Iniciação à Docência de Letras - Língua Inglesa. Doutoranda em Linguística da Universidade Federal do Ceará (UFC); foi pesquisadora visitante na Universidade da Califórnia em Irvine com bolsa da Comissão Fulbright. Possui graduação em Letras - Hab. em Português-Inglês-Literatura pela Universidade Federal do Ceará e mestrado em Linguística Aplicada pela Universidade Estadual do Ceará (UECE). Ministra disciplinas e orienta trabalhos nas áreas de ensino e aprendizagem de línguas estrangeiras, formação de professores, leitura, ensino e novas tecnologias. E-mail: keylamariafrotalemos@gmail.com ORCID: https://orcid.org/0000-0003-1749-8266.

${ }^{* * *}$ Doutoranda em Linguística pelo Programa de Pós-graduação em Linguística (PPGL) da Universidade Federal do Ceará (UFC) e mestra pela mesma instituição. Especialista em Educação a Distância pelo SENAC/ CE (2011). Graduada em Letras Português/Inglês pela Universidade Federal do Ceará (2008). Atualmente é professora do Ensino Básico, Técnico e Tecnológico - EBTT, lotada na Casa de Cultura Britânica na Universidade Federal do Ceará. Tem experiência no ensino de inglês como língua estrangeira, e atua nos seguintes temas: Aquisição, Desenvolvimento e Processamento da Linguagem, Linguística Aplicada, Tecnologias digitais na Educação, Formação de professores, Educação a Distância. E-mail: samelarbp@gmail.com ORCID: https:// orcid.org/0000-0001-9234-6786.
} 
entre fluência e esforço cognitivo na produção escrita em celulares. Foi também observada correlação negativa fraca, não significativa, entre compreensão leitora e fluência de produção escrita no celular; padrão também percebido na relação entre fluência e esforço cognitivo em tablets. Palavras-chave: Correlação; Compreensão leitora; Produção textual; meios digitais

\title{
CORRELATION BETWEEN READING COMPREHENSION AND TEXT PRODUCTION IN DIGITAL MEDIA
}

\begin{abstract}
This study analyzed the correlation between reading comprehension and text production when the processes happened in computers, tablets and cell phones. The research was theoretically based on the cognitive models of text production by Hayes and Flowers (1980) and by Hayes (1996) and the Construction-Integration model by Kintsch (1998). Raw data of two previous and independent studies were used. Study 1 analyzed cognitive effort, measured by the time spent in writing the text, and fluency, measured by the number of words per minute produced in each text. Study 2 counted the number of right answers in reading comprehension texts. Two statistical procedures were used: the Pearson Coefficient and Pairwise. Results indicated a strong positive correlation between fluency and cognitive effort in the production of texts in cell phones. A weak negative correlation was also noticed between reading comprehension and fluency in text production in cell phones; the same pattern was also observed in the relationship between fluency and cognitive effort in tablets.

Key-words: Correlation; Reading comprehension; Text production; digital media
\end{abstract}


Introdução

A visão contemporânea de aquisição da leitura e da escrita incorporam as descobertas sobre aquisição e processamento da informação. A evolução conceitual sobre o assunto conduziu a uma visão integradora da leitura e da escrita como processos inter-relacionados, que não podem mais ser trabalhados separadamente, mas vistos como resultantes da ação do pensamento integrado que é simultaneamente dinâmico e complexo (PUGH; PAWAN, 1991).

Vários estudiosos (KNUDSON, 1998; MARTINO; HOFFMAN, 2002; GRABE, 2003) têm focado suas análises nos componentes de escrita e leitura e nas relações entre elas para entender os efeitos de uma sobre a outra. Apresentam como ponto convergente a assunção de que bons escritores tendem a ser bons leitores e que bons leitores tendem a produzir escritas mais maduras sintaticamente que os leitores com deficiências.

Além dos estudos teóricos, há também um grande número de pesquisas que investigaram a relação entre leitura (sob o viés da compreensão do texto escrito) e produção textual; dentre eles, citamos o de Cunha e Santos (2006), o de Juriati, Ariyanti e Fitriana (2018), o de Mailis, Delfi e Erni (2018), e o de Hutasoit (2020).

Cunha e Santos (2006) utilizaram um texto em cloze para avaliação da compreensão e uma redação dos alunos universitários para avaliar a correção no uso da ortografia, a concordância verbal e a concordância nominal. Os resultados indicaram que quanto menor a compreensão da leitura maior o número de erros nos tópicos gramaticais, evidenciando uma correlação entre essas habilidades.

O estudo de Juriati, Ariyanti e Fitriana (2018) focalizou a correlação entre compreensão leitora e habilidade de escrita. Embora a média de escores no teste de compreensão leitora $(72,47)$ tenha apontado bom desempenho e a média do teste de produção textual tenha sido 61,14 , testes estatísticos utilizando o programa " $\mathrm{R}$ " identificaram os coeficientes de 0.098 com $\mathrm{n}=108$ (df-2 = 106) e nível de significância $(\alpha=0.05)$ de 0.189 , indicando correlação fraca entre as duas variáveis.

Já Mailis, Delfi e Erni (2018) demonstraram haver correlação positiva (coeficiente de correlação, rxy $=0,8$ ) entre compreensão leitora e habilidade de escrita nos recontos produzidos. Os resultados apontam que os estudantes obtiveram bons níveis de compreensão leitora (média $=73,28)$ e de produção escrita (média $=76,12$ ).

Um estudo mais recente (HUTASOIT, 2020) apresentou também coeficiente correlacional entre compreensão leitora e habilidade de escrita de 0.323, implicando que compreensão leitora contribui positivamente para a escrita.

Outras pesquisas (RASINSKI, 2003; PALMER, 2010) também apontaram a presença de correlação positiva entre fluência de leitura e compreensão leitora. Poucos estudos, no entanto, averiguaram a relação entre fluência e/ou esforço cognitivo na produção textual e compreensão leitora.

Um desses estudos é a pesquisa quasi experimental de Palmer (2010), que em seu estudo examinou as relações entre fluência de leitura, fluência de escrita e compreensão leitora. Usando os princípios de avaliação de fluência leitora, 
a pesquisadora elaborou um instrumento de avaliação da escrita que medisse sua fluência entre estudantes de terceira série do ensino fundamental. O estudo buscou analisar as relações entre: $i$ ) a compreensão textual e a fluência leitora; ii) compreensão leitora e fluência de escrita; iii) fluência de leitura e fluência de escrita. Os resultados evidenciaram uma forte correlação positiva entre compreensão e fluência de leitura, além de também constatarem correlação entre compreensão leitora e escrita e entre compreensão leitora e fluência de escrita.

Mais recentemente, a integração das tecnologias digitais ao desenvolvimento da compreensão leitora e das habilidades de produção textual tornou crítica a necessidade de entender-se os efeitos do meio na compreensão leitora e na produção escrita. Pesquisas como as de Delgado et al. (2018), Margolin et al. (2013) e Borges e Lemos (2018) foram desenvolvidas com o objetivo de entender o efeito do meio digital na leitura e sua compreensão. No entanto, os resultados de pesquisas que comparam a compreensão leitora impressa com a digital são diversos, o que torna difícil chegar-se a conclusões.

Delgado et al. (2018) realizaram uma meta-análise na qual examinaram pesquisas feitas entre 2000 e 2017 que compararam a leitura de textos similares no papel e em meios digitais. Os resultados apontaram vantagem da leitura de textos impressos.

Já o estudo de Margolin et al. (2013) comparou resultados em testes de compreensão de textos lidos em papel, computadores e tablets (e-readers) e concluíram que os três meios de leitura não influenciaram na compreensão de textos narrativos e expositivos.

À conclusão semelhante chegaram Borges e Lemos (2018), que buscaram avaliar a compreensão e retenção de conteúdo lido em diferentes meios (impresso, computador de mesa, tablet e celular) de textos acadêmicos e jornalísticos. Os resultados encontrados corroboram a concepção de que não há diferenças significativas entre a leitura no meio impresso ou no meio digital.

Ocrescente uso de tecnologias digitais paraleitura, assim como para produções textuais, fez também crescer o interesse por pesquisas que procurassem entender se, e como, os processos da escrita poderiam ser afetados quando realizados em meios digitais (HANSEN; HAAS, 1988; HAWISHER; SELFE, 1998).

Estudos comparativos entre a produção de um texto manuscrito e sua produção utilizando processadores de textos em computadores demonstraram que o meio utilizado influencia os processos cognitivos de escrita, especialmente os de planejamento e edição. Hansen e Haas (1988) apontam que a produção escrita no computador leva cinquenta por cento mais tempo que a manuscrita. Hawisher e Selfe (1998) verificaram que a revisão do texto foi feita principalmente em relação à construção do sentido, sendo os erros superficiais detectados e corrigidos pelos editores de texto. Além disso, o meio de escrita influenciou a extensão dos textos produzidos, sendo estes mais longos quando produzidos no computador, mas não necessariamente de melhor qualidade.

Com a popularização do uso de processadores de textos e do acesso à Internet, as pesquisas sobre produção escrita em computadores voltaram-se para os gêneros 
e sua produção utilizando esses recursos. Biesenbach-Lucas e Weasenforth (2001) fizeram uma pesquisa comparativa entre produção acadêmica escrita em inglês como segunda língua em e-mail e em processador Word. Os resultados mostram que, pela característica de maior oralidade e objetividade do e-mail, as produções no e-mail foram mais curtas que no processador, apesar de a qualidade do texto não ter sido muito diferente. Wolfe e Manalo (2004) buscaram determinar se havia diferenças significativas nos escores atribuídos se comparada a produção textual no papel com a produção no computador, a partir de um teste TOEFL, e se isso estava relacionado à proficiência linguística.

Outros estudos mais recentes têm sido feitos também focando o uso de software e de escrita na internet, dentre outros. Por exemplo, Chen e Cheng (2008) realizaram um estudo para avaliar a eficácia de um software de avaliação automatizada da escrita para a melhoria da produção em aulas de escrita.

Outro exemplo é o trabalho de Kessler, Bikowski e Boggs (2012), que explorou a natureza da escrita colaborativa baseada na Web. Os resultados mostraram que os participantes trabalharam bem colaborativamente, o que valida essa prática para a inserção na sala de aula.

Em estudo mais recente, Williams e Beam (2019) revisaram 29 pesquisas empíricas, publicadas entre 2002 e 2017, que investigaram o uso de recursos digitais durante aulas e atividades de produção escrita. A análise apontou que o computador e os recursos digitais, incluindo programas de software e ambientes na Web, têm sido utilizados para desenvolvimento da escrita no contexto escolar, o que favoreceu a prática pedagógica de desenvolvimento da escrita.

Infelizmente, poucas pesquisas têm procurado comparar a produção textual em meios digitais diferentes. Um desses estudos foi realizado por Pereira (2016), no qual analisou se, e de que maneira, o esforço cognitivo e a fluência de escrita nos processos cognitivos envolvidos na produção escrita em inglês (L2/LE) são afetados pela tarefa de produção (anúncio, aviso e convite) e pelo meio (celular, tablet e computador). Os resultados indicaram que a tarefa de produção é o principal fator influenciador na quantidade de palavras, e que a fluência de escrita não é influenciada pelo meio, mas pode ser influenciada pela tarefa proposta (gênero textual proposto).

Era de se esperar que o aumento da predominância da cultura digital sobre a cultura impressa e os resultados de pesquisas sobre leitura e sobre produção escrita em meios digitais fizessem surgir questionamentos acerca da relação entre leitura e produção textual quando realizados nesses meios. Surpreendentemente, porém, a busca por pesquisas revelou que há poucos estudos empíricos que comparem a compreensão leitora e a produção de textos quando esses processos são realizados em meios digitais.

Dessa constatação, surgiu o presente estudo que se propôs a investigar preliminarmente a correlação entre níveis de compreensão leitora e fluência e esforço cognitivo na produção textual em computador, tablet e celular. A fim de averiguar essa correlação, foram comparados os resultados obtidos em dois outros estudos, realizados de forma independente: o de Pereira (2016) e 
o de Borges e Lemos (2018), ambos mencionados anteriormente. $\mathrm{O}$ fato de as amostras dos dois estudos serem similares, tanto em número de participantes como na formação acadêmica e linguística desses, e de o acesso aos dados brutos dos estudos ter sido facultado, tornaram possível a realização de testes estatísticos de modo a atingir os seguintes objetivos:

1. Estabelecer a relação entre compreensão leitora e fluência de produção textual quando a leitura e a produção de textos são realizadas em computador, em tablet e em celular;

2. Verificar a relação entre compreensão leitora e esforço cognitivo na produção textual quando as atividades de ler e escrever são feitas em computador, em tablet e em celular;

3. Investigar de que maneira fluência e esforço cognitivo na produção textual em diferentes meios estão relacionados à compreensão leitora de textos nesses mesmos meios.

Com esses propósitos, foram aplicadas as seguintes técnicas estatísticas para análise dos dados brutos: cálculo do Coeficiente de Pearson, para investigação do grau de correlação, e Pairwise, para tratamento dos dados ausentes. O detalhamento desses procedimentos, assim como mais informações sobre os estudos fontes de dados desta pesquisa estão apresentados em "Metodologia". Os resultados obtidos com a realização dos testes estatísticos são analisados e discutidos na seção "Correlação entre compreensão leitora e produção de textos em computador, tablet e celular". Antes, porém, de detalharmos a metodologia da pesquisa, sintetizamos os conceitos, as teorias e os modelos que serviram de base teórica para os estudos cujos dados são correlacionados neste trabalho.

\section{Fundamentação teórica}

Este estudo se fundamenta nas teorias e nos modelos de produção escrita de textos e de leitura e compreensão leitora das pesquisas cujos dados são objeto desta pesquisa correlacional. Portanto, nesta seção são apresentados essas teorias e modelos com o propósito de situar os pressupostos teóricos usados para formulação das hipóteses investigadas.

\section{Modelo cognitivo de escrita}

A análise da produção de textos em meios digitais do estudo "Produção de textos escritos em inglês (L2/LE) em computador, tablet e celular” (PEREIRA, 2016), doravante Estudo 1, fundamentou-se nos modelos cognitivos de produção escrita de Hayes e Flower (1980) e de Hayes (1996).

O modelo de Hayes e Flower (1980) é composto de três partes principais: o contexto da tarefa, a memória de longo prazo do escritor e o processamento 
da escrita. A parte central do modelo é o processamento da escrita. Esta parte possui um elemento (monitor) cuja função é integrar os três principais processos cognitivos: o planejamento, a tradução e a revisão.

O planejamento se subdivide em três componentes: a geração de ideias, a organização, e o estabelecimento de metas. Sua função é estabelecer metas com base na informação fornecida pelo contexto da tarefa e pela memória de longo prazo, e elaborar um plano de escrita que atinja essas metas. O processo de tradução (ou geração do texto) tem a função de converter o conteúdo conceitual, sob a direção do plano de escrita elaborado, em sentenças aceitáveis linguisticamente, isto é, transformar planos em texto escrito. O processo de revisão se subdivide nos subprocessos de leitura e edição. Esse processo objetiva melhorar o texto produzido durante o processo de tradução, detectando erros quanto à gramática, estrutura textual e sentido, enquanto avalia o texto à luz das metas estabelecidas no processo de planejamento.

O modelo proposto por Hayes (1996), no entanto, apresenta mudanças em relação ao modelo de 1980, tais como a ênfase no papel central da memória de trabalho na escrita, a importância dada à motivação e ao afeto, e uma maior organização da seção de processos cognitivos (HAYES, 1996). Enquanto o modelo de Hayes e Flower (1980) apresenta três partes principais, o modelo proposto por Hayes (1996) possui apenas dois grandes componentes: o contexto da tarefa e o indivíduo. Uma das vantagens do modelo de 1996 é a inclusão do meio de produção no contexto da tarefa. Para Hayes (1996), as variações no meio de composição frequentemente podem facilitar ou dificultar o acesso a alguns dos processos que apoiam a escrita. Considerando que no Estudo 1 os meios são digitais, faz sentido buscar-se saber se o processo de planejamento também seria afetado por esses meios.

Uma vez que, no Estudo 1, a produção textual é avaliada em termos de esforço cognitivo e de fluência de escrita, torna-se necessário conceituarmos essas categorias de análise.

\section{Esforço Cognitivo e Fluência de Escrita}

Kellogg (1987) define esforço cognitivo como a quantidade de capacidade atencional alocada a um processo específico em dado momento. Piolat, Kellogg e Fariolli (2001) definem esforço cognitivo como a proporção de recursos executivos disponíveis momentaneamente alocada a um determinado processo. Olive et al. (2009) afirmam que o esforço cognitivo é uma função das demandas da situação de escrita, do conhecimento que o escritor tem do gênero a ser produzido e das habilidades de escrita que o indivíduo desenvolveu, e da extensão da automatização dos processos de escrita pelo indivíduo. Há duas dimensões envolvidas na análise do esforço cognitivo: tempo e desgaste cognitivo (COOPER-MARTIN, 1994). A dimensão de esforço cognitivo considerada no Estudo 1 é o tempo, entendido como a extensão temporal durante a qual são despendidos os recursos cognitivos.

Os trabalhos de Kellogg (1987) e de Olive et al. (2009) são de interesse por causa dos resultados obtidos quanto ao esforço cognitivo, uma vez que no Estudo 
1 também se investigou se, e como, a tarefa de escrita proposta afeta o esforço cognitivo. A partir dos resultados encontrados por Olive et al. (2009) quanto à automatização da escrita, foi ainda averiguado se o meio de produção poderia ser um fator que influenciasse no esforço cognitivo.

Já em relação à fluência na escrita, parece não haver um consenso sobre sua definição (LATIF, 2009), o que tem levado a ser avaliada/mensurada de diferentes formas. Para Latif (2013, p.104), "fluência de escrita pode ser definida operacionalmente como a habilidade do escritor de produzir textos em largos pedaços ou espaços de tempo e é melhor medida usando o comprimento dos episódios de tradução das unidades de produção do escritor". No Estudo 1, a fluência foi medida em termos de taxa de composição (composing rate), isto é, pela quantidade de palavras produzidas por unidade de tempo de escrita, obtida através da divisão do número de palavras no texto pelo número de minutos gastos na escrita. Kellogg (1996, P. 65) afirma que o cálculo da fluência em função da quantidade de "palavras por minuto (wpm) de tempo de composição fornece uma medida média da fluência, uma que inclua todo o tempo de pausa assim como o tempo de fato despendido na execução".

\section{Leitura e compreensão leitora}

No estudo "Compreensão e retenção de informações na leitura de textos em meio impresso e digital” (BORGES; LEMOS, 2018), de agora em diante Estudo 2, a leitura foi entendida como ocorrendo à medida em que o leitor constrói uma representação mental de uma mensagem textual (PERFETTI; LANDI; OAKHILL, 2013). O processo de compreensão, caminho para construção dessa representação do significado do texto, acontece em diversos níveis, desde a identificação de palavras até os processos inferenciais.

Para Kintsch e Rawson (2013, p.228), "a compreensão textual envolve processamento em diferentes níveis". Os autores definem esses níveis como "base textual", "microestrutura", "macroestrutura" e "modelo situacional". No nível linguístico está a microestrutura do texto, que compreende a forma como as palavras estão relacionadas entre si, formando proposições a partir de suas relações sintáticas, semânticas e de coerência. A relação entre as proposições que formam a microestrutura, sua organização em "unidades de ordem superior" (ibid., p.229), forma a macroestrutura, a estrutura global do texto. A microestrutura e a macroestrutura formam a base textual.

Entretanto, a compreensão de um texto vai além do que as palavras no texto tornam evidente; compreendê-las implica apenas tocar a superficialidade da mensagem do autor. Para alcançarmos a compreensão não apenas do explícito, é preciso utilizar nosso conhecimento de mundo, pois muito do que o autor pretende dizer está implícito no texto. A interação entre o conhecimento de mundo do leitor e as informações deixadas pelo autor no texto devem resultar, para que se atinja a compreensão profunda do texto, na construção de um modelo situacional, um modelo mental da situação descrita no texto (KINTSCH; RAWSON, 2013). 
Para construir o modelo situacional do texto, como também para construir a base textual, o leitor precisa fazer inferências, suposições acerca do conteúdo que não está explícito no texto a partir de pistas do próprio texto ou do conhecimento prévio do leitor. A ativação automática do conhecimento para gerar inferências, segundo Kintsch e Rawson (2013), "funciona muito bem desde que o texto se encontre em um domínio bastante conhecido" (p.238). Nesse caso, as inferências podem ser feitas rapidamente.

A avaliação da compreensão leitora no Estudo 2 abrangeu tanto a compreensão da base textual como do modelo situacional, ou seja, da compreensão literal (base textual) à inferencial (modelo situacional).

\section{Metodologia}

Esta pesquisa buscou investigar a correlação entre níveis de compreensão leitora e fluência e esforço cognitivo na produção textual em computador, tablet e celular. Para tanto, foram usados os resultados de dois estudos anteriores e independentes. Nesta seção, primeiramente apresentamos uma síntese da metodologia usada pelos dois estudos cujos resultados estão sendo comparados. Em seguida, descrevemos a formação do corpus pesquisado, as questões de pesquisa, suas variáveis e hipóteses levantadas, e os procedimentos de análise dos dados.

\section{Síntese da metodologia e resultados dos estudos em comparação}

\section{Participantes}

Participaram de "Produção de textos escritos em inglês (L2/LE) em celular, tablet e celular" (PEREIRA, 2016), Estudo 1, 30 (trinta) brasileiros graduandos ou graduados em Letras-Inglês, selecionados a partir de um questionário de perfil. Do estudo “Compreensão e retenção de informações na leitura de textos em meio impresso e digital" (BORGES; LEMOS, 2018), Estudo 2, participaram 37 (trinta e sete) alunos matriculados na disciplina Compreensão e Análise de Textos em Língua Inglesa do mesmo curso do Estudo 1, selecionados pelos mesmos critérios do Estudo 1. Os participantes dos dois estudos tinham entre 19 e 30 anos, nível de proficiência em inglês variando entre B1 e A2 e faziam uso frequente do computador, do tablet e do celular tanto para ler como para produzir textos em português e em inglês.

\section{Geração dos dados}

Os dados do Estudo 1 foram gerados a partir de três tarefas de produção escrita de textos diferentes - um convite, um anúncio e um aviso - elaborados em celular, tablet e computador, conectados à Internet. Para cada meio de composição pesquisado, o participante teve que produzir um gênero textual a ser postado na rede social Facebook. A coleta de dados foi feita individualmente, em sessões de 50 minutos entre a pesquisadora e o(a) participante. Foi adotado o método de gravação de tela para obtenção dos dados, utilizando-se o programa Camtasia 
Studio 8 e o aplicativo Mobizen para que fossem observados os processos de planejamento e tradução durante a produção textual. Para que fosse analisado o esforço cognitivo, foi medido o tempo despendido nesses processos em função da tarefa (gênero textual solicitado) de produção e do meio utilizado. Visando investigar se a fluência no processo de tradução variava em função da tarefa de escrita e/ou do meio de produção, utilizou-se a medida de fluência usada por Kellogg (1996), calculando a média de palavras produzidas por minuto, durante a execução de todas as tarefas e em todos os meios.

Já os dados do Estudo 2 foram gerados em oito momentos ('Tarefas'). Foram lidos dois textos científicos e dois textos jornalísticos nos meios: impresso, computador, tablet e celular. A coleta de dados aconteceu em quatro semanas não consecutivas, no período das aulas, coletivamente com os alunos da turma de Compreensão e Análise de Textos em Língua Inglesa, de uma licenciatura em Letras. Em cada semana de aplicação das tarefas, os participantes leram o texto em um dos meios citados e, em seguida, responderam um teste de compreensão com questões de múltipla escolha. Na elaboração dos testes para avaliação da compreensão dos textos foi utilizado o modelo de Construção-Integração de Kintsch (1998) que considera diversos níveis de compreensão. Dois dias após a leitura do texto, mas na mesma semana, foram realizadas as tarefas de reconto, nas quais os participantes foram solicitados a escrever tudo o que se lembravam do texto lido há dois dias. Os resultados das tarefas de leitura foram analisados de acordo com o número de acertos nas questões dos testes, enquanto os resultados das tarefas de reconto foram analisados de acordo com as chaves de correção, sendo analisados a partir dos conteúdos principais presentes nos tópicos de cada parágrafo e das palavras-chave utilizadas nos textos.

\section{Resultados dos estudos}

Com o intuito de verificar se o esforço cognitivo no processo de planejamento sofria influências do meio no qual a escrita era realizada, foi comparado o tempo despendido nesse processo na produção de cada uma das tarefas realizadas nos meios diferentes. Para determinar em que medida o esforço cognitivo no processo de tradução sofria influência da tarefa de escrita, o tempo gasto na produção da T1 (convite) foi comparado com o da T2 (anúncio) e com o da T3 (aviso) quando realizadas no mesmo meio de composição (celular, tablet e/ou computador). Os resultados e subsequente análise apontam que, no processo de planejamento, tanto o meio quanto a tarefa podem ser fatores de influência para o esforço cognitivo. Já no processo de tradução, o esforço cognitivo foi influenciado pela tarefa de escrita e pelo meio de produção; no entanto, as demandas da tarefa superam as do meio. A análise dos tempos totais indicou que a frequência de utilização de determinado meio para determinadas tarefas (e não somente a frequência de utilização do meio no geral) pode influenciar no tempo gasto para realizálas. Observou-se ainda a tendência de quanto maior for o esforço empregado no planejamento de determinado texto, menor será o tempo gasto no processo de 
tradução. Concluiu-se que o meio de produção foi o fator que mais contribuiu para o aumento do esforço nesta pesquisa.

A fluência foi analisada a partir da quantidade de palavras produzidas por minuto em todas as tarefas e em todos os meios. Foi comparada a média de palavras produzidas por minuto em cada uma das três tarefas (convite, anúncio e aviso) com o propósito de avaliar a relação entre fluência e tipo de tarefa. Também foi comparada a média de palavras produzidas por minuto em cada um dos três meios (celular, tablet e computador) com o objetivo de estudar a relação entre fluência e meio de composição. A análise apontou que a tarefa de produção proposta foi o principal fator influenciador da quantidade de palavras produzidas. Constatou-se que a fluência de escrita não foi influenciada pelo meio de produção.

Os testes de compreensão e de retenção do Estudo 2 foram analisados em relação ao meio (suporte) em que a leitura foi realizada e em relação ao tipo de texto lido (jornalísticos e acadêmicos). Nos testes de compreensão, os alunos acertaram mais questões nas Tarefas 5 (64,1\% na leitura no tablet e $64,8 \%$ na leitura no celular) e 7 ( $68,5 \%$ na leitura no tablet e $65,7 \%$ na leitura no celular) do que nas Tarefas 1 (55,2\% na leitura do texto impresso e 55\% na leitura no computador) e 3 ( $51 \%$ na leitura do texto impresso e $61,1 \%$ na leitura no computador), ou seja, tiveram melhor desempenho na leitura dos textos jornalísticos do que na leitura dos textos acadêmicos. Eles também foram capazes de identificar os temas centrais dos textos jornalísticos - Tarefas 6 (37\% na leitura no tablet e 32,5\% na leitura no celular) e 8 ( $36 \%$ na leitura no tablet e $33 \%$ na leitura no celular) - de forma mais eficiente que na leitura dos textos acadêmicos - Tarefas 2 (31\% na leitura do texto impresso e 30,6\% na leitura no computador) e 4 (43,7\% na leitura do texto impresso e 52,6\% na leitura no computador).

Por sua vez, nos testes de retenção, os alunos tiveram melhor desempenho nos textos acadêmicos (Tarefas 2 e 4); eles foram capazes de recordar os nomes dos teóricos mencionados, mas relembraram menos as palavras-chave dos textos. Já nos testes de retenção dos textos jornalísticos (Tarefas 6 e 8), os alunos foram capazes de lembrar o assunto principal do texto e as palavras-chave, embora não recordassem tanto os detalhes ou os nomes dos envolvidos.

Os resultados evidenciaram que o meio (texto impresso, computador de mesa, tablet, celular) não exerceu mais influência na compreensão do que o gênero do texto lido.

\section{Formação e análise do corpus do estudo correlacional}

Conforme informado anteriormente, o corpus deste estudo foi constituído dos dados brutos dos dois estudos sintetizados: Estudo 1 - "Produção de textos escritos em inglês (L2/LE) em computador, tablet e celular" (PEREIRA, 2016) e Estudo 2 - "Compreensão e retenção de informações na leitura de textos em meio impresso e digital" (BORGES; LEMOS, 2018). Dos dados brutos do Estudo 2, foram desprezados os resultados do teste de leitura do texto impresso e 
do de reconto (avaliação da retenção das informações). Como o propósito deste estudo foi investigar preliminarmente a correlação entre níveis de compreensão leitora e fluência e esforço cognitivo na produção textual em computador, tablet e celular, os resultados das tarefas de compreensão e da tarefa de produção não foram separados em função do gênero textual lido e/ou produzido, mas apenas em relação ao meio em que ocorreram. O corpus ficou assim constituído:

- Pontuação obtida pelos participantes nos testes de leitura (cada teste com 5 questões, podendo os resultados individuais variarem entre 0-5) separada pelos três meios em estudo: computador, tablet e celular;

- Tempo total, expresso em minutos/segundos, gasto na produção dos textos em cada um dos três meios (avaliação do esforço cognitivo na produção textual);

- Total de palavras digitadas por minuto na produção dos textos em cada meio (avaliação da fluência na produção textual).

\section{Questões de pesquisa, suas variáveis e hipóteses levantadas}

Este estudo correlacional buscou responder três questões. A primeira questão - qual a relação entre compreensão leitora e fluência de produção textual quando a leitura e a produção de textos são realizadas em computador, em tablet e em celular? - teve como hipótese a existência de correlação entre compreensão leitora e fluência de produção. Pressupôs-se que quanto maior fosse o nível de compreensão, maior seria o número de palavras por minuto na produção do texto, ou seja, maior a fluência. Foi também levantada a hipótese de que os níveis de compreensão leitora e o número de palavras por minuto na produção textual seriam afetados pelo seu meio de leitura e de produção, sendo os níveis de compreensão maiores em computador do que em tablet e em tablet do que em celular. Também a fluência (maior número de palavras por minuto na produção textual = mais fluente) deveria ser maior em computador do que em tablet e em tablet do que em celular.

A segunda questão - qual a relação entre compreensão leitora e esforço cognitivo na produção textual quando as atividades de ler e escrever são feitas em computador, em tablet e em celular? - partiu do pressuposto de que haveria uma correlação negativa entre compreensão leitora e esforço cognitivo na produção do texto quando o ato de ler e o ato de escrever fossem realizados nos meios digitais em estudo. Acreditou-se que quanto maior fosse o nível de compreensão, menor seria o tempo gasto na produção do texto. A averiguação desse objetivo também teve como hipótese que os níveis de compreensão e o tempo gasto na produção do texto seriam afetados pelo seu meio de leitura e de produção; ou seja, os níveis de compreensão seriam maiores em computador do que em tablet 
e em tablet do que em celular; da mesma forma, o tempo de produção do texto seria maior em computador do que em tablet e em tablet do que em celular.

Já para terceira questão - de que maneira a fluência e esforço cognitivo na produção textual em diferentes meios estariam relacionados à compreensão leitora de textos nesses mesmos meios? - foram estabelecidas as hipóteses de que: i) haveria correlação negativa entre fluência e esforço cognitivo na produção textual; ou seja, quanto maior for a fluência, menor será o esforço cognitivo; ii) existiria correlação entre maior fluência (mais palavras por minuto) e menor esforço cognitivo (menos tempo de produção) na produção textual e o nível de compreensão textual; isto é, quanto maior fosse o nível de compreensão leitora, maior seria a fluência e menor seria o esforço cognitivo na produção textual; e iii) o nível de compreensão leitora e a fluência seriam maiores e o esforço cognitivo seria menor na produção textual quando o meio utilizado fosse o computador do que o tablet e quando fosse o tablet do que o celular.

\section{Procedimentos estatísticos de análise dos dados}

Utilizando o software $\mathrm{R}$, foram realizadas as seguintes técnicas estatísticas:

1. Coeficiente de Correlação de Pearson, medida usada para avaliar a relação linear estatística entre duas variáveis quantitativas. Essa medida que pode variar entre - 1 e 1, indicando o valor 0 que não há correlação entre as duas variáveis. Um valor superior à 0 indica uma correlação positiva; ou seja, à medida que o valor de uma variável aumenta, o mesmo ocorre com o valor da outra variável; um valor inferior à 0 indica uma correlação negativa; isto é, à medida que o valor de uma variável aumenta, o valor da outra variável diminui; e

2. Pairwise, método que se mostra mais eficaz e geralmente menos tendencioso do que a exclusão listwise de acordo com Lance e Vandenberg (2014), pois pode evitar o viés gerado pela imputação de dados ou evitar o viés da exclusão de listwise, que exclui muitos dados. Essa técnica foi utilizada porque, mesmo tendo acesso aos dados brutos dos dois estudos em comparação, faltavam dados que necessitavam ser tratados.

$\mathrm{Na}$ próxima seção, apresentamos os resultados obtidos com a aplicação dessas técnicas e discutimos esses dados à luz das hipóteses levantadas.

\section{Análise e discussão dos dados correlacionados}

Os resultados das técnicas estatísticas aplicadas para correlação dos dados brutos dos dois estudos em análise serão apresentados em forma de resposta à cada questão da pesquisa. Após apresentação dos resultados, esses serão discutidos em relação à(s) hipótese(s) levantada(s). Antes, porém, convém lembrarmos 
que utilizamos o Coeficiente de Pearson como medida para avaliar a relação linear estatística entre duas variáveis quantitativas, onde $p=0$ indica ausência de correlação, $p>0$ aponta correlação positiva (à medida que o valor de uma variável aumenta, o valor da outra também aumenta), $p<0$ mostra correlação negativa (à medida que o valor de uma variável aumenta, o valor da outra variável diminui). Destacamos ainda que, para ser significativa, a correlação deve ter $p>0,7$.

\section{Qual a relação entre compreensão leitora e fluência de produção textual quando a leitura e a produção de textos são realizadas em computador, em tablet e em celular? \\ Com o propósito de respondermos a essa questão, analisamos a relação entre os resultados obtidos nos testes de leitura (número de acertos) e a fluência de escrita (total de palavras digitadas por minuto) na realização dessas atividades em cada um dos meios estudados. Apresentamos os gráficos de dispersão a seguir para melhor visualização da correlação entre essas variáveis.}

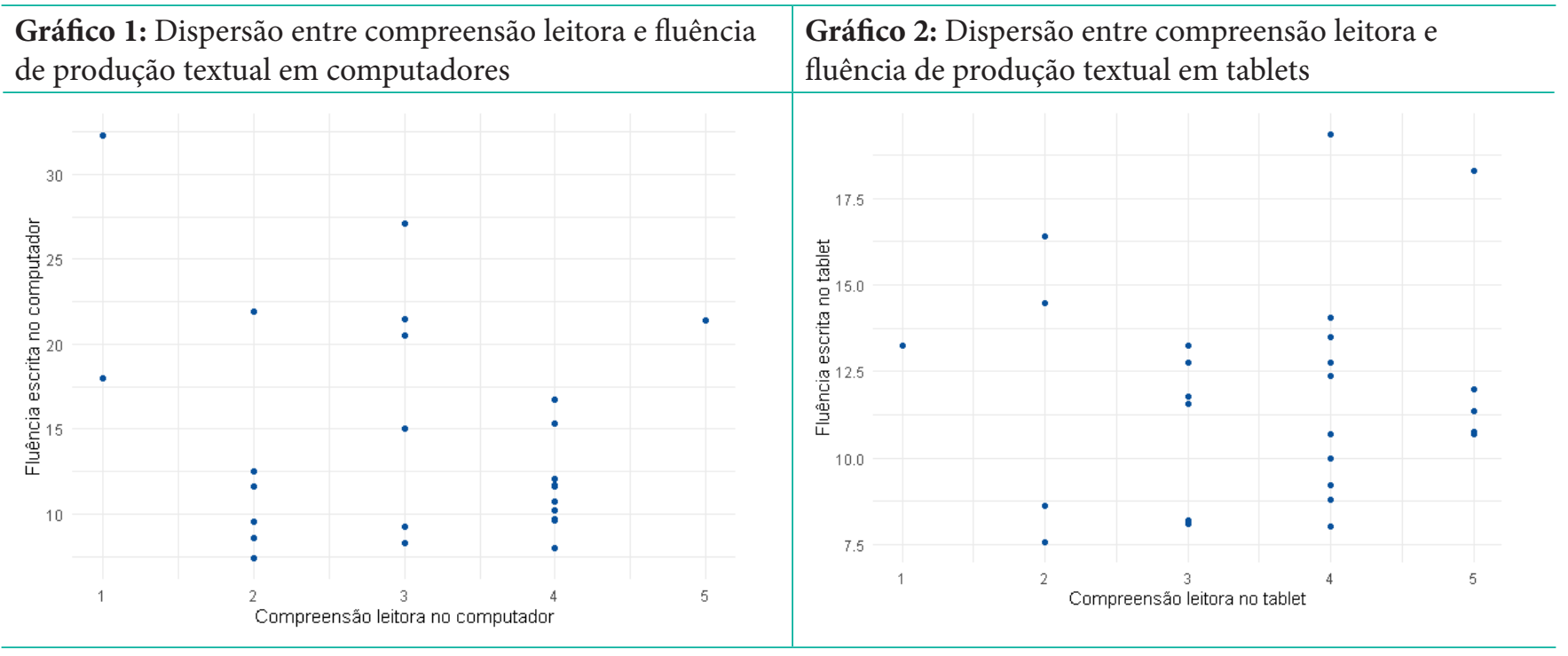

Gráfico 3: Dispersão entre compreensão leitora e fluência de produção textual em celulares.

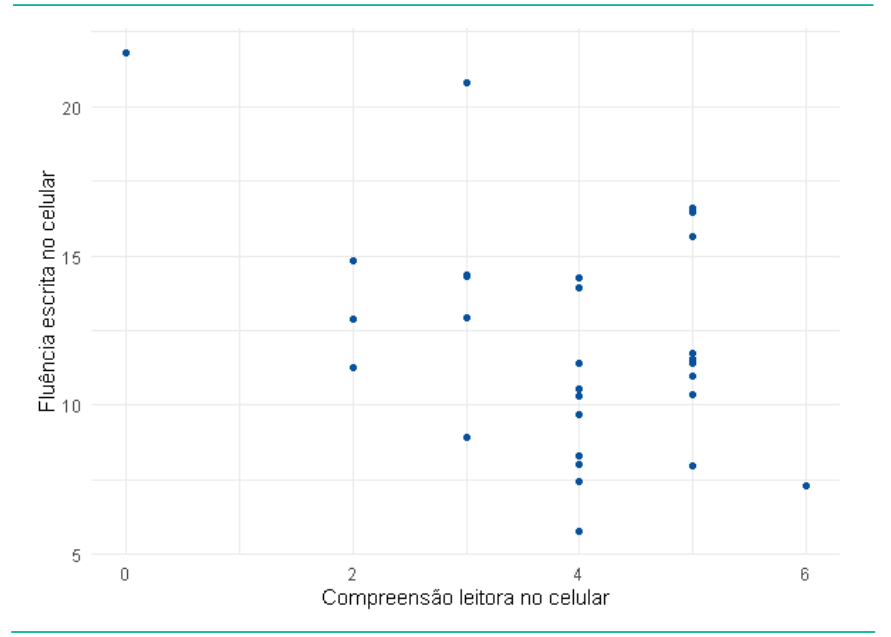


Os resultados mostrados nos Gráficos 1, 2 e 3 não evidenciam haver correlação significativa entre compreensão leitora (resultados do teste de leitura) e fluência de produção textual (total de palavras digitadas por minuto) quando essas atividades foram realizadas em computador $(p=-0,253)$, em tablet ( $p=$ $0,071)$ e nem em celular $(p=-0,445)$. Interessante destacar que, embora não significativa, a fraca correlação entre compreensão leitora e produção textual foi positiva quando essas atividades aconteceram no computador e no tablet, mas negativa e um pouco mais forte em celular. Portanto, não foi possível confirmar as hipóteses de que quanto maior fosse o nível de compreensão, maior seria a fluência, e que os níveis de compreensão leitora e a fluência na produção textual seriam afetados pelo seu meio de leitura e de produção.

Qual a relação entre compreensão leitora e esforço cognitivo na produção textual quando as atividades de ler e escrever são feitas em computador, em tablet e em celular?

A primeira hipótese levantada como resposta a essa questão foi que os níveis de compreensão e o tempo gasto na produção do texto seriam afetados pelo seu meio de leitura e de produção. Para investigarmos essa questão, analisamos a relação entre os resultados obtidos nos testes de leitura (número de acertos) e o esforço cognitivo (tempo gasto, em minutos e segundos, na produção escrita) em relação a todos os meios em que essas atividades foram realizadas. No Gráfico 4 a seguir, evidencia-se que houve grande dispersão entre essas variáveis. Aplicandose o Coeficiente de Correlação de Pearson, obtivemos $p=0,045$, o que nos faz dizer que não evidenciamos correlação significativa entre o esforço cognitivo e a compreensão leitora em meios digitais, apesar de observarmos correlação positiva. Desse modo, não foi possível confirmar a hipótese.

Gráfico 4: Gráfico 4: Gráfico de dispersão entre esforço cognitivo e compreensão leitora

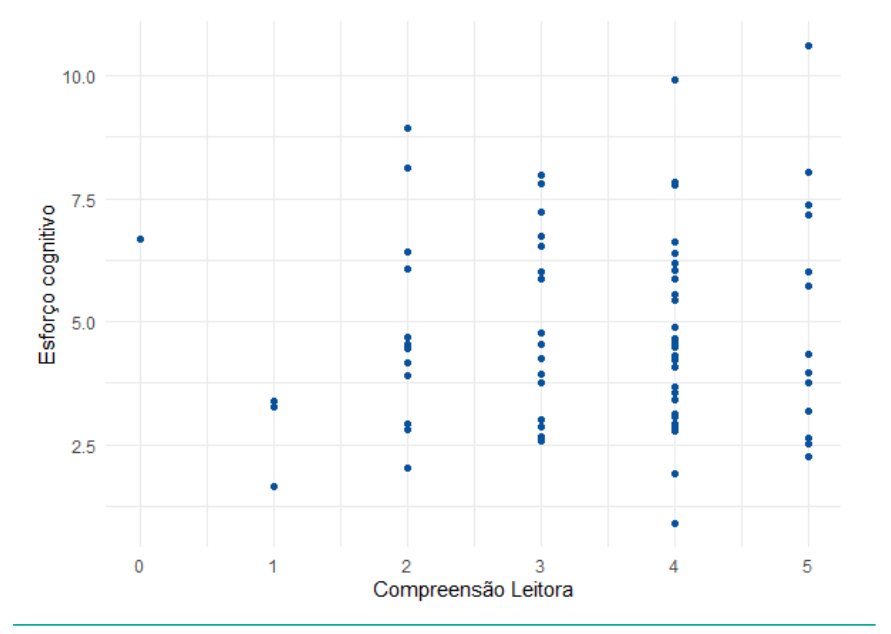


Buscou-se também estudar a relação entre os resultados obtidos nos testes de leitura (número de acertos) e o esforço cognitivo (tempo gasto, em minutos e segundos, na produção escrita) em cada um dos meios em questão. Infelizmente, como pode ser observado nos Gráficos 5, 6 e 7, que se seguem, essa análise não apontou correlação significativa entre compreensão leitora e escrita quando realizadas no computador $(p=0,152)$, no celular $(p=-0,088)$ e nem no tablet $(p=-0,107)$.

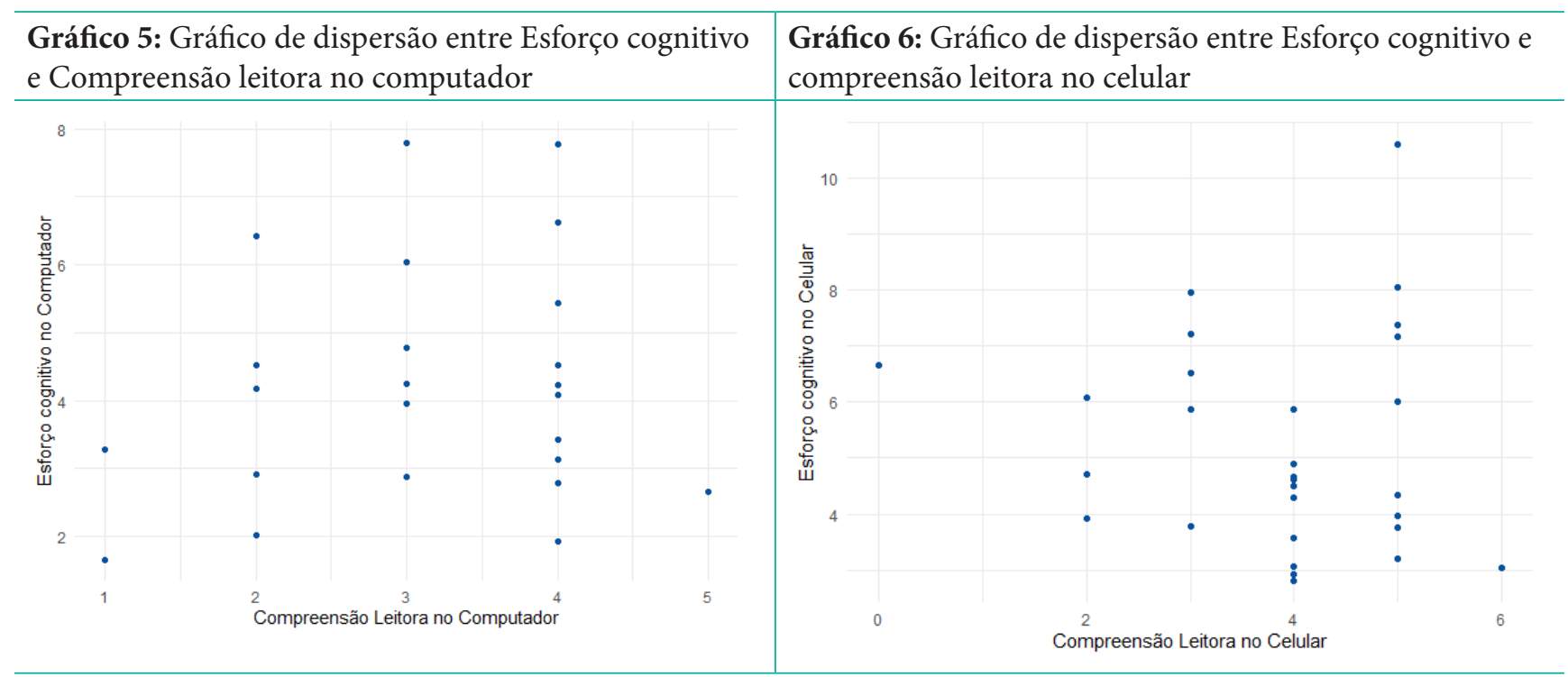

Gráfico 7: Gráfico de dispersão entre Esforço cognitivo e compreensão leitora no tablet

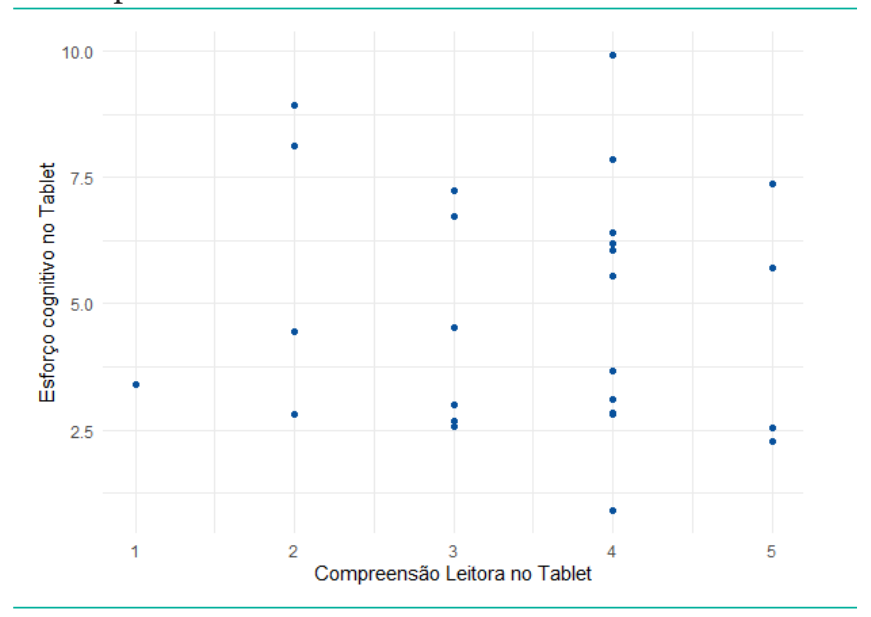

Como mostrado nos Gráficos 5, 6 e 7, tanto no celular como no tablet, há uma tendência de o tempo gasto na produção textual ser menor quanto maior fosse o nível de compreensão, o que confirmaria nossa hipótese se essa correlação fosse significativamente negativa. No computador, porém, a tendência foi de uma fraca relação positiva, mostrando que o tempo de produção foi maior quanto maior foi o nível de compreensão. 
De que maneira a fluência e esforço cognitivo na produção textual em diferentes meios estariam relacionados à compreensão leitora de textos nessas mesmas mídias?

A fim de estudarmos fluência e esforço cognitivo na produção textual em relação à compreensão leitora na realização de leitura e de escrita em meios digitais, analisamos primeiramente a relação entre fluência e esforço cognitivo em cada um dos meios - computador, tablet e celular. A correlação entre fluência e esforço cognitivo (produção textual) em cada meio digital pode ser visualizada nos Gráficos 8, 9 e 10.

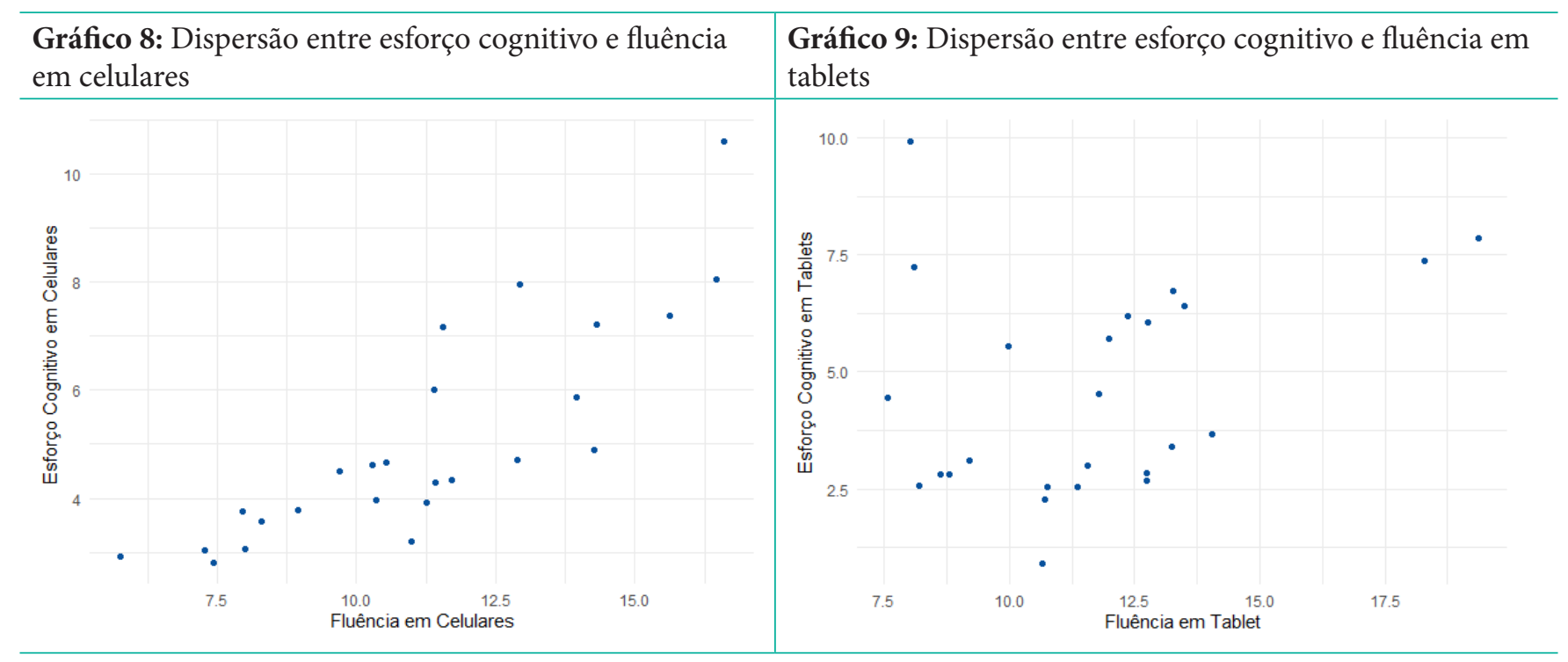

Gráfico 10: Dispersão entre esforço cognitivo e fluência em Computadores

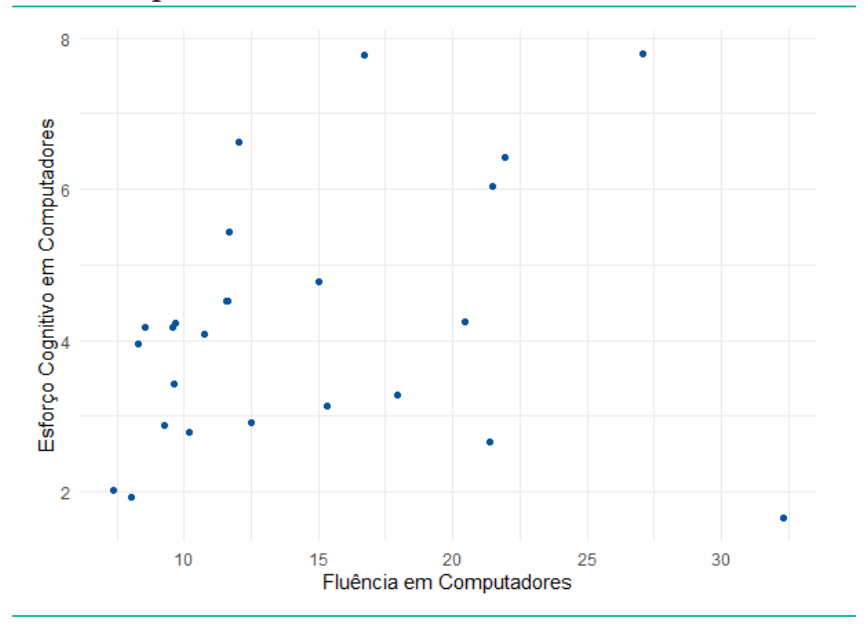

No Gráfico 8, observamos uma correlação entre as variáveis, o que pode ser confirmado na correlação de Pearson, com $p=0,8338$, indicando forte correlação positiva, evidenciando que quanto maior o esforço, maior a fluência na produção textual em celulares. No entanto, o mesmo não foi verificado em relação aos outros meios. Em tablets (Gráfico 9), vemos uma falta de padrão, 
que é confirmada por $p=0,2864$, correlação positiva, porém desprezível. Da mesma forma, em computadores (Gráfico 10), esforço cognitivo e fluência não apresentaram correlação, $p=0,2400$, relação também positiva, mas desprezível.

Com base nesses resultados, dizemos que a hipótese de que haveria correlação negativa entre fluência e esforço cognitivo na produção textual foi rejeitada, pois todas as correlações evidenciadas foram positivas, indicando que quanto maior foi a fluência, maior também foi o esforço cognitivo, embora correlação positiva significativa só tenha sido identificada no contraste das variáveis no celular.

Contudo, já que o objetivo era investigar a relação do esforço cognitivo e da fluência na produção com a compreensão leitora, foi necessário comparar as variáveis esforço cognitivo e fluência com a compreensão leitora em computador, tablet e celular. Os resultados dessas análises estão apresentados nos gráficos que se seguem.

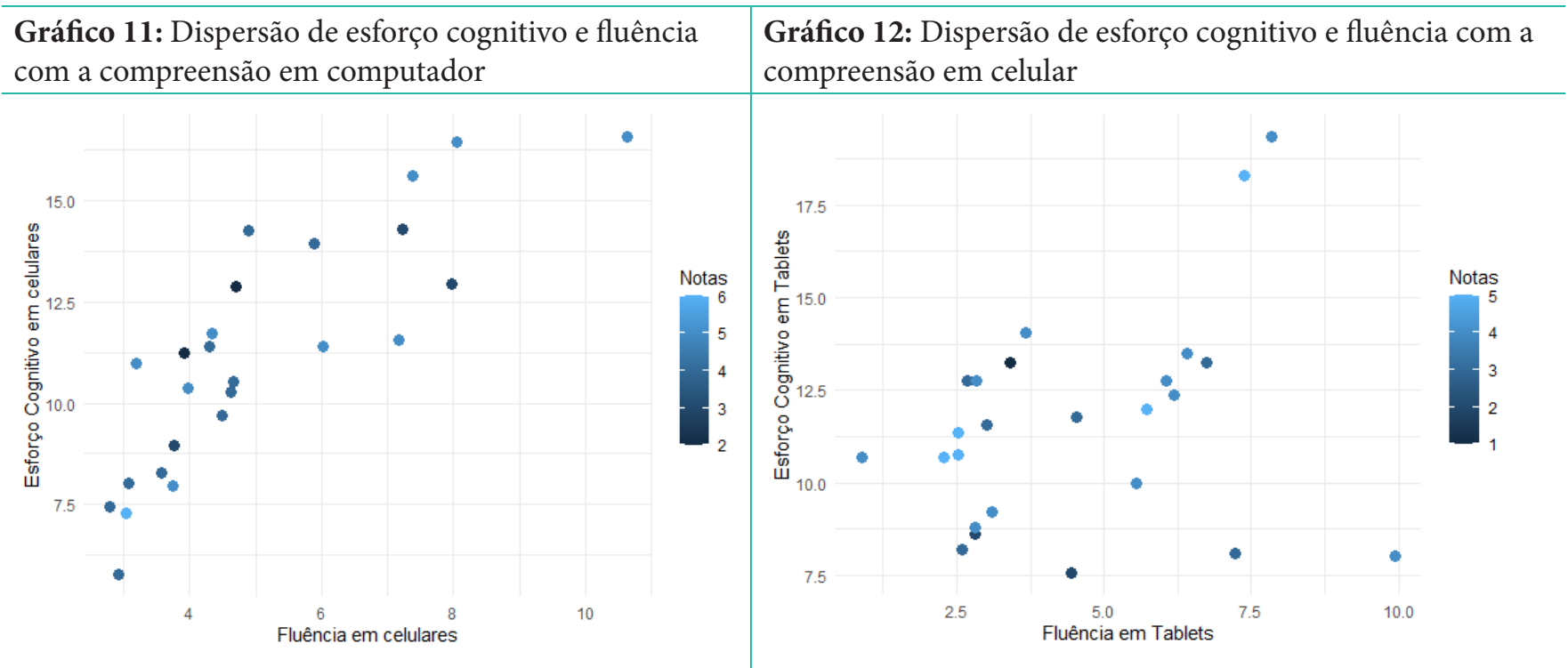

Gráfico 13: Dispersão de esforço cognitivo e fluência com a compreensão em tablet

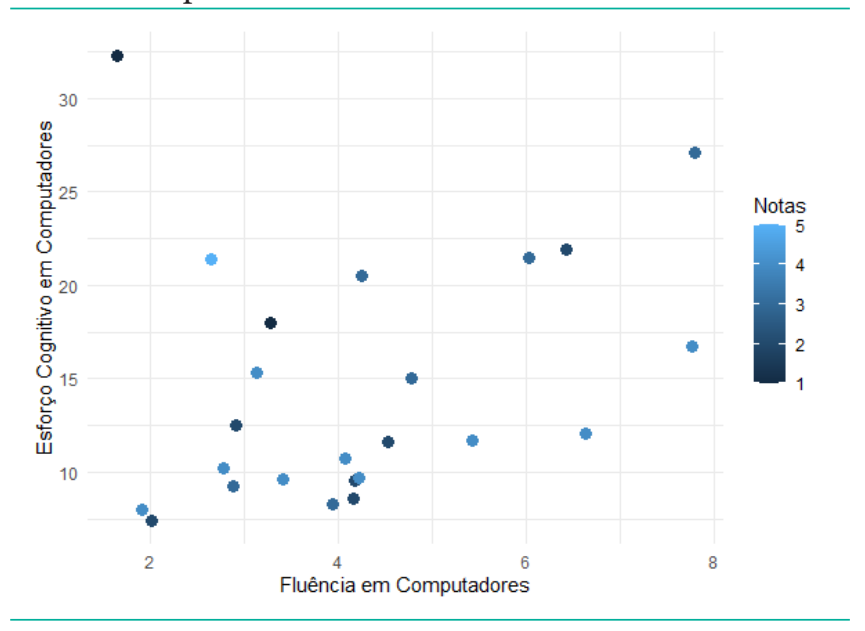

No Gráfico 11, evidenciamos uma falta de padrão na distribuição dos dados, o que nos leva a assumir uma ausência de correlação entre as variáveis 
- esforço cognitivo e fluência e computador, que é confirmada por $p=0,2400$, correlação positiva, porém desprezível. Por outro lado, ao analisarmos o Gráfico 12 , observamos que os participantes com menores notas não demonstram tanto esforço e fluência, mas à medida que o esforço e a fluência sobem, as notas ficam mais pontuais, até chegar a uma única nota 6 para esforço e fluência, mostrando assim que, pelo celular, apesar de os participantes apresentarem tendência a maior esforço, a compreensão do que é lido diminuiu. Essa relação, contudo, não é significativa. No Gráfico 13, podemos perceber a ocorrência de maior dispersão das notas no teste de compreensão, mostrando as menores notas próximas às maiores, apontando falta de correlação entre as notas do teste de compreensão e o esforço e a fluência na produção textual quando essas atividades aconteceram em tablet. Podemos evidenciar que as notas mais baixas se acumulam onde há menor esforço e fluência, evidenciando correlação positiva, mas desprezível.

Desse modo, não foi possível confirmar as hipóteses de que quanto maior fosse o nível de compreensão leitora, maior seria a fluência e menor o esforço cognitivo na produção textual, e de que o nível de compreensão leitora e a fluência seriam maiores e o esforço cognitivo seria menor na produção textual quando o meio utilizado fosse o computador do que o tablet e quando fosse em tablet do que o celular.

\section{Síntese da análise e discussão dos resultados}

Após a realização do estudo entre compreensão leitora e produção textual (fluência e esforço cognitivo) em meios digitais, foi possível evidenciar correlação positiva e forte entre fluência e esforço cognitivo na produção escrita em celulares ( $p=0,8388)$, o que significa que, em celulares, quando a variável de esforço cresce a fluência cresce. Além disso, observamos que a compreensão leitora e fluência de produção escrita no celular possuem uma correlação negativa de $-0,445$, correlação próxima a - 0,5 , o que aponta para uma correlação negativa fraca, que não pode, entretanto, ser assumida; esse padrão também ocorre entre fluência e esforço cognitivo em tablets. Destacamos que os valores obtidos para as demais correlações foram próximos a 0 , ou seja, nossa amostra de dados não possui informação suficiente para que possamos assumir uma correlação significativa entre as variáveis em estudo. Vale ressaltar que uma das metodologias adotadas nesse trabalho foi a de tratamento de dados faltantes via Pairwise, o que implica perda de informação de uma pequena parte da amostra, mas pode evitar um erro de viés que poderia levar a uma conclusão errada sobre os dados.

A seguir, tecemos considerações sobre os resultados obtidos e a metodologia adotada, tecendo implicações para futuras pesquisas.

\section{Considerações finais sobre o estudo correlacional}

Neste estudo, buscou-se investigar preliminarmente a correlação entre níveis de compreensão leitora, medidos pelo número de acertos em teste de 
compreensão, e fluência, avaliada pelo número de palavras produzidas por minuto, e esforço cognitivo, calculado pelo tempo gasto na produção textual, em computador, tablet e celular.

As análises feitas evidenciaram uma forte correlação positiva entre fluência e esforço cognitivo apenas na produção escrita em celulares, o que significa que, em celular, maior esforço cognitivo implicou maior fluência de produção escrita. Foi também observada correlação negativa fraca, não significativa, entre compreensão leitora e fluência de produção escrita no celular; padrão também percebido na relação entre fluência e esforço cognitivo em tablets. Não foi evidenciada correlação significativa entre as demais variáveis em análise. Portanto, não foi possível confirmarmos as hipóteses básicas de que: $i$ ) quanto maior fosse o nível de compreensão, maior seria a fluência na produção do texto, e de que os níveis de compreensão leitora e o número de palavras por minuto na produção textual seriam afetados pelo seu meio de leitura e de produção; $i$ ) haveria uma correlação negativa entre compreensão leitora e esforço cognitivo na produção do texto quando o ato de ler e o ato de escrever fossem realizados nos meios digitais em estudo; e iii) o nível de compreensão leitora e a fluência seriam maiores e o esforço cognitivo seria menor na produção textual quando o meio utilizado fosse o computador do que o tablet e quando fosse o tablet do que o celular.

No entanto, é preciso destacar que, para empreender a análise da correlação entre compreensão leitora e produção textual em meios digitais, foram utilizados dados brutos de dois estudos independentes e anteriores. E daí surge a primeira e grande limitação do estudo. Por se tratarem de estudos independentes, os participantes não foram os mesmos, embora nos dois estudos os participantes estivessem dentro da mesma faixa etária, tivessem níveis de escolaridade próximos e formação semelhante. Desse modo, talvez a comparação feita entre compreensão leitora e produção textual não tenha apresentado correlação entre todas as variáveis em questão devido ao fato de termos comparado a realização desses processos entre pessoas distintas. Além disso, os textos utilizados para leitura e compreensão e os solicitados nas produções não eram do mesmo gênero e/ou tipo. Nas tarefas de leitura e compreensão, foram usados dois textos jornalísticos e dois textos acadêmicos. Já nas tarefas de escrita, solicitou-se a produção de um anúncio, de um aviso e de um convite. Os textos exigidos para leitura e para produção eram, portanto, bastante diferentes, o que pode ter prejudicado uma avaliação mais fidedigna da correlação entre leitura e produção em meios digitais.

Apontadas essas limitações, as perspectivas para futuras pesquisas são facilmente identificadas. Nossa sugestão é de que em próximos estudos, dados tanto do teste de compreensão leitora como das categorias de análise da produção escrita (fluência e esforço cognitivo) sejam coletados entre os mesmos participantes e em tarefas de leitura e de produção textual do mesmo gênero e tipo de texto.

Por fim, é imprescindível considerar-se que este foi um estudo preliminar. Conforme demonstrado na curta e sintética revisão da literatura apontada na 
Introdução deste trabalho, apesar da grande quantidade de pesquisas sobre correlação entre leitura e produção textual, não encontramos outros trabalhos que tenham investigado essa correlação quando a leitura e a produção aconteceram em meios digitais. Desse modo, mesmo que os resultados das análises correlacionais tenham sido de algum modo frustrantes, as limitações detectadas no estudo abrem excelentes possibilidades para futuros estudos.

\section{Referências}

BIESENBACH-LUCAS, S.; WEASENFORTH, D. Email and word processing in ESL classroom: How the medium affects the message. Language Learning \& Technology, v. 05, n. 01, p. 135-165, 2001. DOI: http://dx.doi.org/10125/25115.

BORGES, V. M. C.; LEMOS, K. F. Compreensão e retenção de informações na leitura de textos em meio impresso e digital. Letras em Revista, Teresina, v. 09, n. 01, p. 78-93, 2018. Disponível em: https://ojs.uespi.br/index.php/ler/article/view/198. Acesso em: 27 janeiro de 2021.

CHEN, Chi-Fen E. CHENG, Wei-Yuan E. Beyond the Design of Automated Writing Evaluation: Pedagogical Practices and Perceived Learning Effectiveness in EFL Writing Classes. Language Learning \& Technology, v. 12, n. 2, p. 94-112, 2008. DOI: http://dx.doi.org/10125/44145.

COOPER-MARTIN, E. Measures of Cognitive Effort. In: . Marketing Letters. Kluwer The Netherlands: Academic Publishers, 1994. p. 43-56

CUNHA, N. B.; SANTOS, A. A Relação entre a compreensão da leitura e a produção escrita em universitários. Psicologia: Reflexão e Crítica, Porto Alegre, v. 19, n. 02, p. 237-245, 2006. DOI: https://doi.org/10.1590/S0102-79722006000200009.

DELGADO, P.etal.Don't throw away your printed books: A meta-analysis on the effects of reading media on reading comprehension. Educational Research Review, v.25, p. 23-38, nov/2018. DOI: https://doi.org/10.1016/j.edurev.2018.09.003.

GRABE, W. Reading and Writing Relations: Theoretical perspectives and instructional practices. In Linking Literacies: Perspectives on L2 ReadingWriting Connections. TESL: EJ, v. 7. n. 2, 2003.

HANSEN, W. J.; HAAS, C. Reading and writing with computers: a framework for explaining differences in performance. Communications of the ACM. v. 31, n. 9 , p.1080-1089, 1988. DOI: https://doi.org/10.1145/48529.48532.

HAWISHER, G. E.; SELFE, C. L. Reflections on Computers and Composition Studies at the Century's End. In.: SNYDER, I. (Ed.). Page to screen: Taking literacy into electronic era. Londres: Routledge, 1998. p. 4-19.

HAYES, J. R; FLOWER, L. S. Identifying the organization of writing processes. In.: GREGG, L. W.; STEINBERG, E. R. Cognitive processes in writing. LEA: New Jersey, 1980. p.3-30

HAYES, J. R. A new framework for understanding cognition and affect in writing. In.: LEVY, C. M.; RANSDELL, S. The Science of Writing: Theories, Methods, Individual Differences, and Applications. Routledge: Nova York, 1996. p.1-27.

HUTASOIT, R. A. C. The correlation between reading comprehension e writing ability of tenth grade students of Sma Negeri 11 Palembang. (Tese de doutorado). University of Tridinanti, Palembang, 2020.

JURIATI, D, E.; ARIYANTI; FITRIANA, R. The Correlation between Reading Comprehension and Writing Ability in Descriptive Text. Southeast Asian 
Journal of Islamic Education. v. 01, n. 01, 2018. DOI: https://doi.org/10.21093/ sajie.vli1.1150.

KELLOGG, R. T. Effects of topic knowledge on the allocation of processing time and cognitive effort to writing processes. Memory \& Cognition, v. 15, n.3, p. 256-266, 1987. DOI: https://doi.org/10.3758/BF03197724.

A Model of Working Memory in Writing. In.: LEVY, C. M.; RANSDELL, S. The Science of Writing. Theories, Methods, Individual Differences, and Applications. Routledge: Nova York, 1996. p.57-71

KESSLER, G.; BIKOWSKI, D.; BOGGS, J. Collaborative Writing among Second Language Learners in Academic Web-Based Projects. Language Learning \& Technology, v.16, n.1, p. 91-109, 2012. DOI: http://dx.doi.org/10125/44276.

KINTSCH, W.; RAWSON, K. A. Comprehension. In: SNOWLING, M. J.; HULME, C. A Ciência da Leitura. Porto Alegre: Penso, 2013, p.227-244.

KINTSCH, W. Comprehension: a paradigm for cognition. Cambridge: Cambridge University Press, 1998.

KNUDSON, R. E. College student's writing: An assessment of competence. Journal of Educational Research, v. 92, p. 13-19, 1998. DOI: https://doi. org/10.1080/00220679809597571.

LANCE, C.E.: VANDENBERG, R.J. (Eds.). More Statistical and Methodological Myths and Urban Legends: Doctrine, Verity and Fable in Organizational and Social Sciences (1st ed.). Routledge, 2014.

LATIF, M. M. A. Toward a New Process-Based Indicator for Measuring Writing Fluency: Evidence from L2 Writers' Think-Aloud Protocols. The Canadian Modern Language Review/LaRevue canadienne des langues vivantes, v. 65, $\mathrm{n}$. 4, p. 531-558, 2009. DOI: $10.3138 / \mathrm{cmlr} .65 .4 .531$.

.What Do We Mean by Writing Fluency and How Can It Be Validly Measured? Applied Linguistics. v.34, n.1, p.99-105, 2013. DOI: https://doi.org/10.1093/ applin/ams073.

MAILIS, M.; DELFI,S.; \& ERNI,E. B. The correlation between reading comprehension and writing ability of the second year students of Sman 1 Muaro Sentajo Teluk Kuantan in recount texts. Journal Online Mahasiswa, v. 5, n. 1, 2018. Disponível em $<$ https://jom.unri.ac.id/index.php/JOMFKIP/article/view/17211 $>$. Acesso em 02 de fev. de 2021.

MARGOLIN, S. J. et al. E-readers, computer screens, or paper: Does reading comprehension change across media platforms? Library Publications and Presentations, v. 24, 2013.

MARTINO, N. L.; HOFFMAN, P. R. An investigation of reading and language abilities of college freshmen. Journal of Research in Reading, v. 25, p. 310-31, 2002. DOI: https://doi.org/10.1111/1467-9817.00178.

OLIVE, T. et al. Children's cognitive effort and fluency in writing: Effects of genre and of handwriting automatisation. Learning and Instruction, v.19, p. 299-308, 2009. DOI: https://doi.org/10.1016/j.learninstruc.2008.05.005.

PALMER, L. O. The relationship between reading fluency, writing fluency, and reading comprehension in suburban third-grade students. Tese (Doutorado). University of San Diego, CA, 2010.

PEREIRA, S. R. B. Produção de textos escritos em inglês (L2 e LE) em celular, tablet e computador. Dissertação (Mestrado em Linguística). Programa de PósGraduação em Linguística da Universidade Federal do Ceará, 2016. 
PERFETTI, C. A.; LANDI, N.; OAKHILL, J.. A aquisição da habilidade de compreensão da leitura. In: SNOWLING, M. J.; HULME, C.. (Orgs.) A Ciência da Leitura. Porto Alegre: Penso, 2013, p.245-265.

PIOLAT, A.; KELLOGG, R. T.; FARIOLLI, F. The triple task technique for studying writing processes: on which task is attention focused? Current Psychology Letters, v. 4, p. 67-83, 2001. Disponível em <https://www.researchgate.net/ publication/28764028_The_triple_task_technique_for_studying_writing _ processes_On_which_task_is_attention_focused $>$. Acesso em 14 de março de 2021.

PUGH, S. L.; PAWAN, F. Reading/writing \& academic literacy. In R. F. Flippo \& D. C. Caverly (Eds.), College Reading \& Study Strategy Programs. Netwark, CA. 1991.

RASINSKI, T. The fluent reader: Oral reading strategies for building word recognition, fluency, and comprehension. New York: Scholastic, 2003.

WILLIAMS, C.; BEAM, S. Technology and writing: Review of research. Computers \& Education, v. 128, p. 227-241, 2019. DOI: https://doi.org/10.1016/j. compedu.2018.09.024.

WOLFE, E. W.; MANALO, J. R. Composition medium comparability in a direct writing assessment of non-native English speakers. Language Learning \& Technology, v. 8, n. 1, p. 53-65, 2004. DOI: http://dx.doi.org/10125/25229. 